\title{
CRISIS, CONVIVENCIA MULTICULTURAL Y «EFECTOS DE BARRIO». EL CASO DE DOS BARRIOS DE VALENCIA
}

\section{CRISIS, MULTICULTURAL COEXISTENCE AND «NEIGHBOURHOOD EFFECTS». THE CASE OF TWO NEIGHBOURHOODS OF VALENCIA}

Francisco Torres Pérez, Albert Moncusí Ferré y Fernando Osvaldo Esteban*

Resumen: La inserción urbana de los inmigrantes se desestabiliza y se pone a prueba con la crisis y las politicas aplicadas. Si bien en Valencia se mantiene una convivencia tranquila, la situación de los servicios públicos aumenta la competencia por recursos escasos entre vecinos de diferentes orígenes. Este texto presenta, en el marco de la ciudad de Valencia, un análisis comparativo de dos barrios receptores de inmigrantes que presentan fuertes contrastes. Por un lado, Russafa un barrio céntrico popular y en proceso de gentrification; por otro, Els Orriols, un barrio periférico obrero. Aún con muchos rasgos comunes, la intensidad del recelo hacia el inmigrante varía de un barrio a otro en función de su ambiente social y de su marco socio-urbano.

Palabras clave: convivencia multicultural, efecto de lugar, crisis, Valencia.

* Departament de Sociologia i Antropologia Social. Universidad de Valencia. francisco.torres@uv.es ; Albert.Moncusi@uv.es ; Fernando.Esteban@uv.es 


\begin{abstract}
The urban integration of immigrants is destabilized and tested by crisis and the policies implemented. While a peaceful coexistence continues in Valencia, the situation of public services increases competition for scarce resources between residents of different backgrounds. In this context, this paper presents a comparative analysis of two immigrant neighbourhoods that exhibit strong contrasts. One, Russafa a popular downtown neighbourhood in process of gentrification; the other, Els Orriols, a worker suburb. Despite their many common features, the intensity of suspicion toward immigrants varies from one neighbourhood to another depending of their social environment and socio-urban frame.
\end{abstract}

Keywords: multicultural coexistence, neighbourhood effects, crisis, Valencia.

\title{
1. INTRODUCCIÓN
}

En las últimas dos décadas, el vecindario inmigrante ha protagonizado una de las transformaciones centrales de Valencia. Según el Padrón Municipal, los 103.944 vecinos extranjeros en enero de 2013 suponían el 13,1\% del vecindario. Como otras grandes ciudades españolas, Valencia se ha convertido en una urbe multicultural y la mayoría de los nuevos vecinos y vecinas han engrosado los sectores con una situación socioeconómica precaria. Aunque no sin tensiones, menores, su inserción urbana ha sido tranquila con una distribución residencial desigual y una creciente inclusión como vecinos.

En la actualidad, dada la política aplicada ante la crisis, los recortes en servicios públicos y la extensión de la precariedad social, la inserción urbana de los inmigrantes se desestabiliza y se pone a prueba, tanto a nivel de ciudadanía local como de convivencia cotidiana.

Nuestra hipótesis es que los mayores recelos frente a los vecinos inmigrantes se derivan de la situación de los servicios públicos y que su intensidad depende de otros aspectos de la vida local. En ese sentido, ¿vivir en una u otra área de la ciudad es un elemento significativo que modula, de forma más incluyente o excluyente, el recelo frente al inmigrante? Dicho de otra forma, ¿operan efectos de barrio? 
Para responder presentamos la situación en la ciudad de Valencia y, en este marco, un análisis comparativo de dos barrios receptores de inmigrantes con fuertes contrastes. Por un lado, Russafa un barrio céntrico popular y en proceso de gentrification; por otro, Els Orriols, un barrio periférico obrero.

Este artículo se basa en resultados del Proyecto UV-INV-PRECOMP12-80741, «La convivencia multicultural en tiempos de crisis. Análisis comparativo de dos barrios de Valencia», y para el nivel de ciudad, del Proyecto «Metrópolis glocalizadas: el caso de Valencia. Espectacularización y precarización urbana en las ciudades medianas», CSO2009-10715. En cada barrio se han realizado diez entrevistas, tanto individuales como grupales, a miembros de asociaciones y vecinos inmigrantes, observación de espacios y actos significativos, entre octubre de 2012 y diciembre de $2013^{1}$. A nivel de ciudad, diez entrevistas a técnicos, profesionales e informantes significativos, así como resultados de un cuestionario remitido a los CMSS, Centros Municipales de Servicios Sociales, y las Memorias de Servicios Sociales y de Cáritas entre 2005 y 2011.

\section{EFECTOS DE BARRIO}

En Estados Unidos y Europa los estudios sobre los «efectos de barrio», basados en la idea que habitar una zona urbana u otra influye en las trayectorias sociales de sus vecinos, han conocido un importante desarrollo a partir de los años 90. En la tradición de la ecología social, la literatura anglosajona sobre los neighbourhood effects se ha centrado en estudios cuantitativos sobre logros escolares, trayectorias laborales, tasa de delincuencia, etc., de los habitantes de barrios pobres. Igualmente, se han realizado estudios cualitativos como el ya clásico de Wilson, 1987, sobre inner-city y underclass en Chicago o los estudios sobre barrios en diversas ciudades europeas (Musterd y Andersson, 2005; Van Ham et al, 2012). Desde una perspectiva distinta, Wacquant (2007) subraya la dimensión socio-espacial del gueto. Respecto a los hijos de los inmigrantes, Portes y Rumbaut (2010)

1 La codificación de las entrevistas remite a su ámbito y número, ECn para Valencia ciudad, ERn para Russafa y EOn para Els Orriols. 
destacan la relevancia del contexto urbano en su incorporación o no al mainstream norteamericano.

En Francia, los estudios cuantitativos sobre los efectos de barrio son mucho más escasos (Vallet, 2007). Sin embargo, un eje vertebrador de la literatura sobre la banlieue, lo constituye los effets de lieu (Bourdieu, 1993), la relación entre la estratificación social y la distribución espacial desigual de actores, bienes y servicios, que se interioriza como habitus. Los numerosísimos estudios cualitativos sobre banlieue muestran como vivir en un barrio connotado negativamente ha tenido claros efectos negativos sobre los hijos de los inmigrantes (Blanc et al, 2007; Body.Gendrot y Whitol, 2007). Los escasos estudios cuantitativos franceses, en la tradición anglosajona, se han centrado en las formas de convivencia, de socialización e identitarias ligados al barrio (Authier, 2007).

La existencia de efectos de barrio no suele discutirse pero su relevancia, sus procesos causales y las dificultades de su determinación son objeto de vivos debates (Van Ham et al, 2012). Estos debates remiten, a menudo de forma implícita, al marco conceptual que se adopta. En los estudios cuantitativos, éste determinará las variables que se utilicen; en los cualitativos, el cuadro donde inscribir, explicar y valorizar las percepciones de los residentes.

En nuestro trabajo, entendemos que los efectos de barrio se encuadran en un marco macro-estructural y de ciudad. La inserción urbana de los inmigrantes depende de factores estructurales (ciclo económico, mercado inmobiliario), institucionales (normativa de extranjería, servicios públicos) y otros (percepción social), que operan en el marco de una ciudad con su particular estratificación socio urbana. Asimismo, la conformación concreta de estos factores depende de los procesos de interrelación, acomodación y ajuste mutuo, en contextos "cara a cara» que tienen en el barrio un espacio social privilegiado.

En el marco del debate norteamericano, Manski (2000) diferencia entre «efectos contextuales» $\mathrm{y}$ «endógenos», composición social $\mathrm{y}$ «ambiente social», $\mathrm{y}$ «efectos correlacionados», derivados de la accesibilidad territorial a bienes y servicios. Musterd et al (2006) abordan el barrio como Estructura de Oportunidades Territoriales en tanto que espacio donde mercado, sociabilidad y acción pública adquieren unas características específicas. En su estudio sobre exclusión y barrios populares españoles Blanco y Subirats (2011) adoptan similar perspectiva. Inspirándonos en estos autores, consideraremos 
relevantes un conjunto de factores que ordenamos en dos grupos: el ambiente social y el marco socio-urbano.

$\mathrm{El}$ ambiente social incluye el nivel socioeconómico de sus habitantes, la edad, el género, el origen inmigrante y la sociabilidad. Destacamos la sociabilidad tanto como recurso como en su dimensión de convivencia. Este ambiente social es indisociable de un marco socio-urbano específico por la calidad de las viviendas, los equipamientos y servicios con que cuenta el barrio, su ubicación y comunicaciones. Uno y otro aspecto se conforman mutuamente. El marco socio-urbano como espacio vivido genera dinámicas, prácticas e imágenes sociales, que facilitan o dificultan a sus vecinos la accesibilidad a los bienes y procesos que conforman la ciudadanía local.

\section{LA VALENCIA INMIGRANTE. DEL BOOM A LA CRISIS}

Valencia se consolida como ciudad multicultural en la primera década del siglo xxi. Si en 2000 los vecinos extranjeros de Valencia representaban el 1,5\% del total, en 2013 suponían el 13,1\%. Desde el inicio, los inmigrantes se instalan en una diversidad de espacios que podemos agrupar en tres tipos ${ }^{2}$. Uno, los barrios más modestos del centro histórico, como El Pilar y El Mercat; un segundo tipo, barrios populares semi-centrales como Russafa y, un tercer tipo constituido por barrios obreros periféricos, de vivienda VPO de los años 60 y 70, como Camí Fondo (Torres, 2007).

2 Esta tipología es similar a la de otras ciudades españolas como Madrid (Observatorio Migraciones Madrid, 2007) y europeas como Paris (Guillon, 1995; Simon, 1998), Milán y Turín (Arbací, 2008), aunque parcialmente diferente a la de Barcelona y Bilbao, muy marcada por la centralidad de Ciutat Vella y San Francisco, respectivamente (Torres, 2011). 


\section{Cuadro 1}

NÚMERO Y PROPORCIÓN DE VECINOS EXTRANJEROS EN VALENCIA Y ALGUNOS BARRIOS SIGNIFICATIVOS. 1996-2012

\begin{tabular}{|l|c|c|c|c|c|c|c|c|c|c|}
\hline & \multicolumn{2}{|c|}{1996} & \multicolumn{2}{c|}{2000} & \multicolumn{2}{c|}{2004} & \multicolumn{2}{c|}{2009} & \multicolumn{2}{c|}{2012} \\
\hline & Ext & \% & Ext & \% & Ext & \% & Ext & $\%$ & Ext. & $\%$ \\
\hline Valencia & 6.821 & 0,9 & 11.251 & 1,5 & 71.746 & 9,1 & 123.348 & 15,1 & 108.449 & 13,6 \\
\hline 1.4 El Pilar & 88 & 2,3 & 119 & 3,2 & 546 & 14,2 & 735 & 18,1 & 714 & 16,6 \\
\hline 1.5 El Mercat & 40 & 1,4 & 109 & 3,7 & 494 & 15,0 & 570 & 16,9 & 565 & 16,2 \\
\hline 2.1 Russafa & 367 & 1,5 & 548 & 2,4 & 3.972 & 15,6 & 4.525 & 18,0 & 3.870 & 15,7 \\
\hline 3.2 La Roqueta & 70 & 1,1 & 87 & 2,1 & 823 & 17,6 & 952 & 20,9 & 888 & 20,0 \\
\hline 4.3 Calvari & 72 & 1,3 & 102 & 2,0 & 679 & 13,0 & 1.353 & 25,2 & 1.153 & 22,7 \\
\hline 5.1 Marxalenes & 51 & 0,4 & 163 & 1,5 & 1.344 & 11,6 & 2.246 & 19,6 & 1.871 & 17,0 \\
\hline 5.2 Morvedre & 128 & 1,3 & 208 & 2,1 & 1.332 & 12,5 & 1.849 & 17,3 & 1.662 & 15,8 \\
\hline 7.3 Tres Forques & 43 & 0,5 & 70 & 0,8 & 820 & 9,1 & 2.116 & 22,3 & 1.935 & 21,3 \\
\hline 7.4 Fontsanta & 15 & 0,4 & 55 & 1,3 & 370 & 10,2 & 903 & 23,9 & 861 & 23,4 \\
\hline 10.1 Montolivet & 169 & 0,9 & 288 & 1,5 & 2.415 & 12,0 & 4.084 & 19,9 & 3.475 & 17,6 \\
\hline 10.2 En Corts & 132 & 1,2 & 210 & 2,0 & 1.469 & 12,5 & 2.818 & 22,2 & 2.397 & 19,5 \\
\hline 11.5 Nazaret & 24 & 0,4 & 48 & 0,8 & 469 & 7,5 & 1.651 & 23,5 & 1.323 & 20,3 \\
\hline 12.4 Camí Fondo & 63 & 1,7 & 101 & 2,6 & 668 & 14,9 & 926 & 19,6 & 835 & 18,1 \\
\hline 15.1 Els Orriols & 119 & 0,7 & 219 & 1,4 & 2.758 & 16,3 & 5.740 & 31,2 & 4.387 & 25,8 \\
\hline
\end{tabular}

Fuente: Padrón Municipal. Ayuntamiento de Valencia.

A partir de 2005, estos barrios han estabilizado su vecindario extranjero, al tiempo que serán nuevos barrios obreros y periféricos los que la aumenten (Els Orriols en el norte, Natzaret en los Poblats Marítims y Tres Forques y Fontsanta en el oeste; mapa 1). Las razones son diversas: la trama de vivienda barata céntrica ya estaba colmatada, sus precios habían aumentado y su número se reducía por el lento pero continuo proceso de mejora urbana de las áreas centrales.

Estos barrios receptores de inmigrantes se han conformado como barrios multiculturales. Algunos, como Russafa desde mediados de los años 90 y Els Orriols más recientemente, constituyen lugares de «centralidad inmigrante» (Toubon y Messamah, 1990) por la presencia de comercios étnicos, lugares de culto y espacios de sociabilidad. 


\section{MAPA 1}

\section{BARRIOS DE VALENCIA DE RENTA BAJA, MEDIA-BAJA Y DE INMIGRANTES}

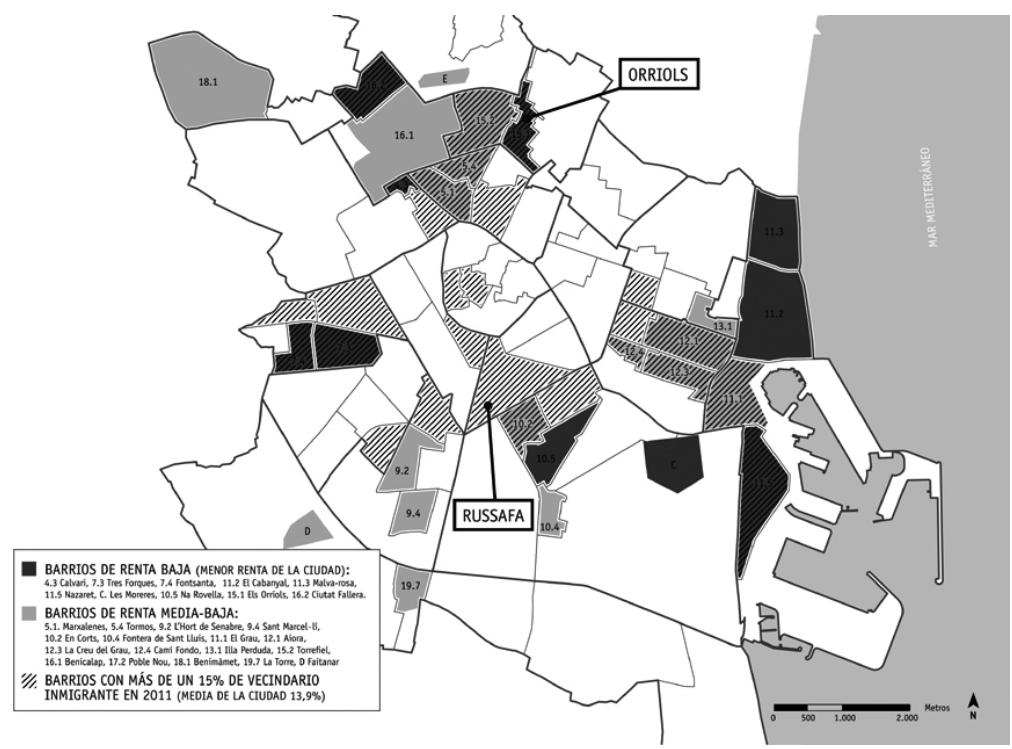

Fuente: Proyecto «Metrópolis glocalizadas: el caso de Valencia». CS02009-10715.

En Valencia, la dinámica urbana se caracteriza por el uso compartido de los espacios públicos sin tensiones pero sin interrelación significativa. Este uso común se ha combinado con concentraciones de personas del mismo origen que resignifican el espacio (Delgado, 1998), como las canchas latinas y de rumanos en varios parques o el ambiente magrebí alrededor del oratorio y las tiendas halal en Russafa o en Els Orriols. Estos últimos espacios son los que han suscitado mayor recelo, aunque Valencia no ha conocido la tensa controversia de otras ciudades españolas (Moreras, 2011).

Además de incorporarse a los espacios públicos, los inmigrantes y sus hijos son usuarios habituales de colegios públicos, centros de salud y de servicios sociales. Esta mayor demanda se ha concentrado en centros públicos de barrios populares ya deficitarios y con una respuesta tardía e insuficiente de la Administración. Estos problemas han tenido repercusión ciudadana, desde comentarios recelosos 
a dinámicas de huida de algunos colegios, aunque el proceso se fue asentando con aspectos positivos como compartir prestaciones y espacios de vecindad significativos (Torres, 2007; Moncusí, 2009).

Por otro lado, la imagen que nos dibuja la prensa valenciana es menos positiva que la coexistencia tranquila en sus calles. Entre 2003 a mayo 2014, entre las noticias sobre los inmigrantes en Valencia destacan las referidas a concentración o incremento de inmigrantes $(18 \%)$, situaciones de vivienda precaria (15\%), pobreza $(8 \%)$ y otras en proporción menor ${ }^{3}$. Esta imagen de precariedad ha aumentado en los últimos años.

La crisis económica en Valencia, agudizada por el fracaso del modelo de ciudad neoliberal espectacular (Cucó, 2013), se sintetiza en la bancarrota del Ayuntamiento, 1.046 millones de deuda (Boletín Banco de España 2012-III), y en una política municipal que ha aumentado los precios de los servicios y reducido las frecuencias del transporte, la limpieza o el mantenimiento de parques. Por otro lado, la tasa de paro en la ciudad ha ascendido hasta el 25,2\% (EPA 2014-I), por debajo de la media de la Comunidad Valenciana 28\%, pero con un $65,5 \%$ de parados de larga duración.

Los impactos de la crisis adquieren un mayor rigor para los vecinos inmigrantes por su situación socioeconómica media más precaria, la mayor incidencia del paro y sus efectos más «desestabilizantes» (por ejemplo, para renovar permisos).

Un primer indicador de estos impactos es la reducción de vecinos inmigrantes, como ha sucedido en otras grandes ciudades españolas. Después de alcanzar su máximo histórico en 2009, el vecindario extranjero se ha reducido un $13,7 \%$ hasta 2012, destacando el descenso de latinoamericanos. Sin embargo, este diagnóstico basado en la nacionalidad se atenúa si consideramos los vecinos empadronados nacidos en el extranjero. En este caso, la reducción es menor, 4,6\%, como consecuencia de la importancia de las nacionalizaciones.

Otro indicador lo constituye la situación de los servicios. En los Colegios Públicos, con la reducción de profesorado y de recursos, han desaparecido las actividades de apoyo educativo con incidencia en una parte de los hijos de inmigrantes (Montero, 2013). Respecto a la asistencia sanitaria, si bien la Generalitat aprobó un programa para paliar la exclusión de indocumentados, sus efectos han sido

3 Con la base de datos Factiva se han trabajado 621 referencias de los diarios Levante, Las Provincias, ABC, EL Mundo y El País. 
limitados. En 2013 se habían registrado 182 casos de denegación de atención sanitaria en la ciudad de Valencia (ODUSALUD, 2014).

La extensión de la pobreza en la ciudad afecta a familias autóctonas e inmigrantes. Respecto a éstas, en los CMSS se constata «una involución de su situación», mayor precariedad y aumento de situaciones de indocumentación sobrevenida (lo que excluye de prestaciones como la Renta Garantizada de Ciudadanía). En diversos CMSS se destaca que «viene más gente normalizada que dice solo ayudáis a los gitanos y a los inmigrantes» (EC6). En Cáritas, si bien la prensa local ha dado mucha relevancia al aumento de españoles, la mayoría de atendidos continua siendo inmigrantes y, entre ellos, aumentan los «que ya habían conseguido la condición de regulares, pero que ahora no tienen trabajo, no pueden renovar (el permiso)». En Cáritas, como en los CMSS, «ante recursos escasos y repartiendo miseria... pues el pobre españolito que acude a la Cáritas parroquial se siente invadido» (EC8).

\section{RUSSAFA. ¿DE BARRIO MULTICULTURAL A BARRIO CHIC?}

Barrio popular, semi-céntrico y de tradición artesanal, Russafa perdía población desde los años 70. Sin embargo, desde mediados de los años 90, la población se estabilizó y la animada vida de calle y la intensa actividad económica revivieron aunque modificadas. A los vecinos de «toda la vida» se sumaron un número creciente de vecinos extranjeros y algunos jóvenes profesionales. Al mismo tiempo, algunos de los problemas del barrio se hacía más evidentes: déficit de plazas escolares, falta de zonas verdes excepto la plaza M. Granero, ausencia de locales cívicos y un tráfico caótico.

Desde estos años, la sociabilidad en Russafa presenta una doble cara, común y específica. La primera, la copresencia cotidiana de vecinos de diferentes orígenes que comparten las calles, el Mercado o la plaza M. Granero, es ampliamente mayoritaria, tranquila y consolidada como cotidianeidad (Torres, 2007). Al mismo tiempo, algunas calles de Russafa evocaban la imagen de Park del mosaico, pequeños mundos que se tocan pero no se interrelacionan. En 2004 había en Russafa 191 negocios étnicos, concentrados espacialmente y diferenciados por colectivos. Esto facilitó la conformación de cuatro 
micro áreas de sociabilidad específica: magrebí, senegalesa, china y latina. Más allá de su actividad comercial, los negocios étnicos constituían un espacio de sociabilidad, información y relaciones.

Junto a esta inserción tranquila, no faltaron los problemas. Aparte de pequeñas tensiones vecinales, sin particular incidencia, la sociabilidad masculina de calle magrebí que se vinculaba con inseguridad focalizó el recelo entre 2000 y 2003. Más tarde, la situación se normalizó (Torres, 2007). Durante estos años la extrema derecha valenciana intentó vincular problemas del barrio y presencia de inmigrantes. Russafa fue el escenario de varias manifestaciones ultras en 1997, 2002, 2003 y 2006, con escaso apoyo vecinal pero con un amplio debate, diversas respuestas unitarias y una dinámica de concertación entre diferentes asociaciones, entre ellas de inmigrantes. En esa dinámica no faltaron los desacuerdos pero consolidó una red de relaciones y contactos entre los diferentes grupos.

A partir de 2005, dos dinámicas están transformando Russafa. Por un lado, el proceso de gentrificación de un sector del barrio. Por otro, la reducción relativa de su carácter inmigrante como consecuencia de este proceso, de la crisis y otros factores.

La centralidad de Russafa se ha visto revalorizada por el Parque Central que supone el soterramiento de las vías del tren hasta la Estación del Norte, colindante con el barrio, y la urbanización y ajardinamiento de los $681.036 \mathrm{~m}^{2}$ liberados. Dado su costo el proyecto está paralizado desde hace años pero, recientemente, se ha aprobado el ajardinamiento del sector más cercano a Russafa. El barrio ha mejorado en estos años: la reforma integral del CP Balmes, la apertura de un Centro Juvenil y otro de Mayores, la reurbanización de calles y la rehabilitación de edificios (ahora relantizada). En 2007, es estableció una oficina municipal que promovió estudios, algunos muy contestados, y canalizó ayudas hasta su cierre en 2012, por falta de fondos. Todo ello ha atraído a vecinos más acomodados, la mayoría jóvenes. Russafa se ha consolidado, así, como uno de los barrios de renta media de la ciudad (Ayuntamiento de Valencia, 2002; Torres y García, 2013). A estos nuevos vecinos hay que añadir los profesionales y artistas que ahora trabajan en Russafa. Ya en los 90 se instalaron algunos pintores pero desde hace cinco años han proliferado los estudios de diseñadores y artistas. En 2014, se celebró la cuarta edición de Russafart, una bienal artística con participación de 53 locales del barrio. Además, han proliferado los comercios fhasion y los locales de copas. En unas calles estos locales han sustituido a 
los comercios étnicos; en otras se da una osmosis inestable entre el bar popular, el restaurante halal, el estudio sala de exposiciones y la «vinoteca».

Este proceso se valora, en general, como positivo. Al mismo tiempo, algunos miembros de asociaciones, tanto inmigrantes como autóctonas, destacan su incidencia en el encarecimiento de los alquileres, el ruido generado y la lejanía que perciben en estos nuevos vecinos y usuarios respecto «a las cosas del barrio... ellos van a la suya... no están en [la reivindicación del] CP Puerto Rico» (ER4).

Por otro lado, entre 2009 y 2012, Russafa ha perdido el 18,7\% de su vecindario extranjero. Sin embargo, si atendemos a los vecinos empadronados nacidos en otro país la reducción es menor, del $11,8 \%$. Tanto en un caso como en otro, el mayor descenso corresponde a los latinoamericanos. En términos generales, este descenso de vecinos inmigrantes se atribuye a «la crisis y porque aquí los precios se han puesto muy caros» (ER6). Una parte muy importante, un $70 \%$ de las bajas, se ha trasladado a otros barrios de Valencia según el Padrón. En otros casos, minoría, se trata de movilidad transnacional. Muchas familias ecuatorianas y bolivianas han vuelto, se nos dice, a sus países. "Se quedaron sin paro, sin nada... y como no encontró trabajo, ni horas... pues, entonces, se fueron» (ER3). No todo son retornos; varios varones latinoamericanos han emigrado a un país europeo aunque la familia continúa en el barrio:

«se fue S. de electricista a Alemania y viene cada dos meses, viene... por ahora mi hermana no se va, está contenta con el barrio, el colegio, nosotras... así están dos años ... él va y viene y $\mathrm{M}$ y los niños aquí» (ER7).

En varias familias marroquíes, el padre en paro continúa en Valencia pero la mujer e hijos se han ido a Marruecos que «es más barato y tienen la familia» (ER6). En estos casos, latinos y marroquíes, son estrategias de reproducción familiar transnacional que mantienen la relación con el barrio.

En opinión de una vecina marroquí, «ahora el barrio está como más español»(ER6). Esta percepción está muy vinculada a la reducción de comercios étnicos que han pasado de 191 en 2004 a 121 en 2013. Han cerrado los comercios mayoristas chinos, los bazares al por mayor, las teterías y tiendas más modestas. Las causas de este proceso son diversas. Con la reurbanización de las calles y la 
ampliación de las aceras, las operaciones de carga y descarga frente a los comercios mayoristas originaron embotellamientos, protestas y multas; al mismo tiempo, los gestores locales «animaron» a los comerciantes a trasladarse a las afueras ${ }^{4}$. Otros comercios étnicos han cerrado por dificultades económicas y otros por el cambio de Russafa como barrio de centralidad inmigrante. Es el caso de las carnicerías halal cuya clientela «ya tienen carnicería (halal) en su pueblo (área metropolitana) y, claro, es más cómodo comprar en tu pueblo...aunque vengan a la mezquita» (R6).

Muchos de los rasgos que caracterizan a Russafa como barrio inmigrante se mantienen. Las tiendas halal, restaurantes y bazares más importantes continúan. La "comunidad musulmana», alrededor del oratorio y la asociación Averroes, está bien asentada. $\mathrm{Al}$ norte del barrio, se mantienen los grupos de senegaleses. Otras sociabilidades muy visibles en el barrio hasta 2005, como la latina alrededor del Mercado y la china en calle Cuba y Sueca, se han diluido. Sin embargo, ambas constituyen comunidades asentadas como muestran, además de los vecinos empadronados, tres paradas latinas en el Mercado de Russafa o un colegio privado orientado al alumnado de origen chino (y pudiente).

Otro rasgo que se mantiene es la convivencia tranquila, la rica y diversa trama asociativa y el dinamismo del barrio, con diversas iniciativas comerciales (Russafa kids, Russafa gay), vecinales (Jornada multicultural, Carnaval y otras), artísticas (Russafart) y festivas (fallas). Sin embargo, como en el pasado, esta pluralidad de iniciativas y dinámicas se dan en paralelo entre los diversos grupos. Al mismo tiempo, las campañas impulsadas por la Plataforma por Russafa por la mejora del parque M. Granero, entre 2007 y 2008, y la construcción del CP Puerto Rico, entre 2008 y 2011, han constituido una dinámica barrial compartida. Los dos temas, ya conseguidos, constituían reivindicaciones históricas del barrio y han agrupado a vecinos de diferentes orígenes en las recogidas de firmas, las actividades lúdico-reivindicativas o en los dos referéndums realizados.

Según nuestros interlocutores, la crisis no ha «cambiado la buena convivencia en el barrio y en el colegio» (R5). Los vecinos inmigrantes, como las familias más modestas autóctonas, han reducido gastos a los imprescindibles y se recurre al apoyo familiar, de sus

4 Los mayoristas chinos y magrebíes se han trasladado al polígono industrial de Manises, colindante con el aeropuerto. 
redes de connacionales y/o comunitarias y de Servicios Sociales. En el CMSS Ciutat Vella, del que depende Russafa, constatan una mayor demanda de todos los grupos de vecinos, sin destacar a los inmigrantes. Sin embargo, quizás no de forma generalizada, se constata un malestar sordo. Una vecina boliviana de Russafa, Valencia, lo cuenta así:

«el ambiente (del barrio) bien, como siempre... la crisis no... bueno con las ayudas... oyes comentarios en el mercado... que si se lo dan todo a los inmigrantes y me dan ganas de decirles: que no me dan nada, que me toca (bueno, yo no, mi hermana)... que me toca por hijos... por baremo que se dice, ¿no?... eso duele así como dentro» (ER7).

Es difícil dilucidar el futuro de Russafa. Como ha ocurrido en tantos barrios es muy posible que su carácter inmigrante se reduzca o desaparezca con la gentrificación en marcha. Sin embargo, en barrios como Raval (Barcelona) y Goutte d'Or (Paris) la presencia inmigrante continúa incluso tras décadas de intervenciones (Tapada-Berteli y Arcaci, 2011; Bacqué y Fijalkow, 2006). Algunos de los factores que operan como el arraigo y antigüedad del vecindario inmigrante, la actitud activa de una parte del vecindario -incluidos algunos de los nuevos vecinos de clase media- que han limado los aspectos más agresivos de las intervenciones, la vitalidad de las redes vecinales, los aspectos contradictorios de las políticas públicas, etc., están también presentes en Russafa.

\section{ELS ORRIOLS: REAFIRMANDO CARÁCTER PROLETARIO Y MULTICULTURAL}

Els Orriols es un barrio obrero donde, en los años 60, se instalaron inmigrantes de Andalucía y Castilla La Mancha en bloques de viviendas VPO construidos por el arquitecto Barona. El parque urbano refleja ese carácter obrero: un $60,12 \%$ de edificios fueron construidos entre 1961 y 1970 y el $62,26 \%$ tiene menos de $80 \mathrm{~m}^{2}$. Vivir en las «casas de Barona», nombre popular del barrio, estuvo connotado negativamente: 
«En realidad Barona es Orriols... A la gente no le gusta llamarlo Barona porque era... lo peor que había en Valencia. Siempre decían "no vayas a Barona”... Mi madre no me dejaba cruzar Primado Reig porque Barona era lo peor que había... En la época de la heroína aquí hizo estragos» (EO1).

La llegada de población extranjera a partir de 2000 introdujo un componente multicultural e invirtió una dinámica de pérdida de habitantes. A partir de 2005, Els Orriols fue el barrio de la ciudad con una mayor proporción de vecinos extranjeros, con un máximo del $31,2 \%$ en 2009 , principalmente ecuatorianos pero también bolivianos, colombianos y, en los últimos años, rumanos. La presencia de Valencia Acoge, la apertura en 2005 del Centro Cultural Islámico (CCI), la más reciente de un templo sikh y de la Oficina de Extranjería de Delegación del Gobierno, el creciente número de comercios étnicos y de inmigrantes en sus calles, contribuyó a ese perfil multicultural. Este mosaico lo completan algunos gitanos españoles.

Además, aunque la convivencia tranquila preside sus calles, la plaza o las puertas de los colegios, la prensa amplificó algunos fenómenos aislados de violencia atribuyéndolos a pandillas latinoamericanas. En forma distinta al pasado, la mala imagen del barrio resurge. Es frecuente apuntar ese contraste en comparación con Russafa5:

«Este barrio tiene mala fama. Así como Russafa aunque tenga una inmigración poderosa, digámoslo así, ... no sé por qué, al estar más cerca del centro, al ser un barrio más histórico... Hay mucha gente que vive de allá al lado y le dices hay una tienda que está muy bien, ahí... y te dice, ¡¿Dónde?, ¿ahí dentro?!» (EO1).

Históricamente, Els Orriols ha sido uno de los barrios pobres de Valencia (Ayuntamiento de Valencia, 2002). Desde 2008, el barrio ha experimentado la crisis de forma cruda. Desde el CMSS Salvador Allende se detecta un impacto muy acusado del desempleo, de

5 Este contraste también se aprecia en la prensa local. Desde 2009 a 2012 las noticias sobre Russafa destacan la presencia o cierre de negocios étnicos (18\%) y la concentración de inmigrantes (16\%). También el número de inmigrantes centra las noticias sobre Els Orriols (25\%) pero seguidas de los actos de la extrema derecha $(22 \%)$ y de las «bandas latinas» $(11 \%)$. Mientras un barrio adquiere su dimensión multicultural principalmente por su actividad comercial, en el otro caso las referencias son más negativas. 
dificultades económicas y demandas de necesidades básicas. Estas situaciones también llegan a Valencia Acoge:

«La gente viene y sus necesidades no son ni el tema de los papeles, ni el tema de aprender castellano o valenciano o tal. El tema es "no tengo para comer, no tengo para dar de comer a mis hijos, no puedo pagar el alquiler, tengo una deuda de no sé cuántos, no sé cuántos requerimientos de desahucio"... de desesperación» (EO2, traducido del valenciano).

Se trata del barrio que más desalojos ha vivido cada semana (Levante, 28/11/12). Muchas viviendas han quedado vacías; varias de ellas han sido ocupadas ilegalmente por españoles, payos o gitanos, o por extranjeros. «Hay mucha masificación de gente y mucho piso patera, mucho inmigrante... aquí tenemos de todo» (EO3). Muchos de los antiguos propietarios o inquilinos eran extranjeros que han visto truncadas sus trayectorias. Algunos se han quedado compartiendo piso pero otros han regresado a sus países o se han dirigido a otros países europeos, quedando aquí sus familias, en estrategias similares a las ya comentadas para Russafa. De hecho, según datos de padrón, entre 2009 y 2012, Els Orriols perdió un 23,6\% de población extranjera y un 15,6\% de nacido en el extranjero. Como Russafa, el padrón refleja también un incremento de naturalizaciones como estrategia para optimizar oportunidades sea en España o en otros países europeos.

Es fundamental, también, la cuestión del desempleo. Rascanya, distrito que incluye Orriols, tenía un paro registrado del 23,6\% en 2013, entre los más elevados de la ciudad y con un mayor y rápido deterioro en los últimos años. Al paro y al cierre de comercios aluden repetidamente nuestros entrevistados para ilustrar un panorama económico desalentador. El carácter multicultural de Orriols se ha problematizado más:

«porque no hay trabajo, entonces otra vez hay peleas y disputas... Antes... nadie quería ir a recoger naranjas, nadie quería ir a trabajar a la obra... Sobran los inmigrantes porque no hay faena y el que no quería ir a recoger naranjas ahora mata por recoger naranjas» (EO3). 
Otro factor son las carencias en servicios e infraestructuras. El nuevo Centro de Salud, que debía substituir al antiguo ubicado en un bajo con aluminosis, ha retrasado su apertura más de un año por falta de fondos. Con los recortes en becas escolares y ayudas sociales en general, la competencia se da también en lo social:

«Tienes que ser pobre de solemnidad... para que te den una mínima ayuda de comedor... ¿Quién es pobre?... muchos inmigrantes que se han quedado sin sus redes ... y no veas los comentarios: "se lo han dado a ellos". Y eso está creando una mala convivencia» (EO1).

Más allá de lo apuntado, el boom inmobiliario que experimentó Valencia dejó huella en Els Orriols. Como en otras zonas de la ciudad, en una parte de huerta colindante con el barrio, se construyeron torres de condominios con piscina y parque privado, lo que se conoce como «Nuevo Orriols». A juzgar por nuestras entrevistas, parte de sus residentes son antiguos vecinos de otras zonas del barrio que buscaron mejor calidad de vida. Existe, pues, un Orriols de clase media e incluso media-alta, sin relación con el viejo barrio obrero y que ha acaparado las actuaciones e inversiones. Entre nuestros entrevistados no faltan las quejas sobre lo que se considera una injusta marginación institucional.

«el problema es que lo que te venden cuando te hablan de Orriols son las viviendas que van a hacer, la nueva ampliación del campo del Levante [nuevo Orriols]... Todo eso es lo único que cuenta a la hora del barrio, porque el Orriols de toda la vida, donde está la clave, la gente del barrio que siempre ha estado, no existe. A nivel de Administración no existe» (EO3).

Recientemente, el partido ultraderechista España 2000 ha centrado sus iniciativas en Els Orriols. A finales de 2014 organizó una entrega de alimentos «solo para españoles». Ataviados con petos de "ONG», militantes de la organización repartieron alimentos a los que portaran DNI y acreditaran desempleo. En el momento del reparto, improvisaron otros requisitos: ser payo, blanco y no tener origen extranjero. El acto tuvo gran repercusión en prensa y televisión. En nuestras entrevistas se constata la existencia de simpatizantes de la extrema derecha que apoyaron el acto, sin 
apenas voces de oposición pero con malestar entre el vecindario. Semanas después una parte organizada de los vecinos convocaron una marcha, con fiesta final, bajo el lema "Orriols convive: por la integración, contra el racismo y la xenofobia». Esa respuesta fue gestada en la Asamblea de barrio formada a principios de 2014, en el marco de un proyecto europeo dirigido desde Valencia Acoge. Se trata de una iniciativa que persigue generar cohesión y mejorar las condiciones de vida y la que participan vecinos, entidades del barrio y plataformas como 15M Orriols, Asamblea de parados o Plataforma de Afectados por las Hipotecas. La Asamblea ha realizado diferentes actividades, como exposiciones, charlas, talleres diversos, conciertos y cine en un descampado abandonado, y diferentes acciones en defensa de la educación pública y a favor de la renta básica.

Esta Asamblea de barrio, formalizada en 2015 como asociación, se está erigiendo en punto de apoyo y coordinación entre entidades y pretende implicar desde las fallas, las asociaciones de vecino, las Asociaciones de Padres y Madres de colegios y otras surgidas en los últimos años. Entre estas últimas, además de las ya nombradas, habría que destacar el Centro Cultural Islámico, la Iglesia Evangélica, la Asociación de Sierra Leona, la Asociación de Mujeres africanas o la Asociación Marroquí de Orriols. En este barrio obrero, la dimensión étnica y cultural se cruza de forma particular con lo social tanto en los impactos de la crisis como en la acción comunitaria.

Els Orriols no es la inner-city anglosajona o la banlieue francesa como tampoco lo son, en términos generales, los barrios populares de las ciudades españolas (Blanco y Subirats, 2011). Sin embargo, Els Orriols presenta similitudes con otros barrios obreros periféricos como Ciudad Meridiana (Barcelona) o San Cristóbal de los Ángeles (Madrid), donde se exacerba el impacto de la crisis, la escasez de recursos y el recelo hacía el inmigrante (Cano y García, 2012). Asimismo, estos barrios presentan aunque con mucha menor intensidad, de momento, similares tendencias a las subrayadas para la banlieue francesa: la retroalimentación entre las condiciones espaciales y socio-urbanas del barrio, la condición social y socio-étnica de sus vecinos y la estigmatización como lugar de residencia, influye desfavorablemente en las trayectorias sociales de sus habitantes (Bacqué y Denjean, 2006; Blanc y otros, 2007; Body-Gendrot y Whitol de Wenden, 2007). 


\section{CONCLUSIONES. CRISIS, RECELO AL OTRO Y «EFECTOS DE BARRIO»}

A nivel de Valencia, la inserción urbana de los inmigrantes mantiene sus rasgos centrales aunque con cambios. Se ha reducido el vecindario inmigrante y ha aumentado su movilidad, en diversos sentidos. A diferencia del pasado reciente, son los barrios periféricos y obreros los que presentan una mayor proporción de vecinos extranjeros; una tendencia anterior a la crisis pero que parece haberse exacerbado con esta. Los espacios públicos de la ciudad y otros aspectos de la vida local continúan caracterizándose por una convivencia pacífica pero distante. Sin embargo, la situación de los servicios públicos es más ambigua. Los CMSS, Cáritas y otros actores constatan el aumento de competencia entre vecinos de distintos orígenes por ayudas sociales y su expresión en términos de resignificación negativa del inmigrante, lo que aparece como clara fuente de posibles tensiones etnificadas. Un resultado coherente, por otro lado, con otros estudios a nivel estatal (Cea y Vallés, 2011).

A nivel de barrio hemos presentado la situación de Russafa y Els Orriols dos barrios de inmigrantes con distinto lugar en el mapa socio-urbano de Valencia y con dinámicas divergentes.

Russafa es un barrio socialmente heterogéneo, que ha visto aumentar sus vecinos de clase media, profesionales y artistas. El paro y las dificultades económicas son perceptibles pero también la apertura de nuevos locales de ocio, artísticos o profesionales. Por su parte, Els Orriols es un barrio periférico obrero con intensa percepción de crisis por el paro, las dificultades económicas y el número de desahucios. A las diferencias socio-económicas hay que añadir las diferencias del marco socio-urbano. En el caso de Russafa, beneficiado por su centralidad, el aumento de equipamientos, la reurbanización de calles y el proceso de gentrificación han generado una clara percepción de dinamismo y mejora del barrio. Por el contrario, en la periferia, el centro obrero de Els Orriols se siente y ha estado postergado por la preferencia de la Administración por el «nuevo Orriols», una zona de clase media. Els Orriols obrero continúa con carencias graves en servicios y equipamientos.

Estas diferencias también afectan al vecindario inmigrante. Con una inmigración instalada desde hace más de 20 años en Russafa, una parte de ella está muy arraigada. Si por un lado, ha disminuido su número y su visibilidad, por la reducción de negocios étnicos, por 
otro lado su inclusión en el barrio no es objeto de debate aunque se constaten tensiones sordas por ayudas de Servicios Sociales. La imagen multicultural continúa siendo destacada por los gestores públicos, junto a la comercial y la artística, como uno de los atractivos del barrio (Arazo, 2011). Por el contrario, Els Orriols acoge a una inmigración más reciente, una parte en proceso de asentamiento y con conflictos identificados con pandillas latinas. En este caso, las tensiones parecen más evidentes y presentes en la vida cotidiana; no sólo referidas a las ayudas sociales, sino también a la competencia por el trabajo (que no tiene su espacio social en el barrio pero que, sin embargo, repercute en él).

Si bien la convivencia tranquila conforma la cotidianidad en los dos barrios, la imagen negativa del inmigrante como competidor por recursos escasos y el recelo frente a él parece mayor en Els Orriols que en Russafa. Entre los factores que nos explican esta diferente percepción cabe destacar la distinta composición socioeconómica, el diferente impacto de la crisis, la calidad de equipamientos y del marco socio-urbano, la percepción de estar atendidos o ignorados por la Administración, la visión sobre los vecinos inmigrantes y las dinámicas sociales recientes. La extrema derecha valenciana sabe lo que hace al centrar en Els Orriols sus últimas iniciativas.

En el caso de Valencia, el recelo frente al inmigrante en tiempo de crisis se modula de forma diferente según el barrio. Nuestra investigación cualitativa constata efectos de barrio como consecuencia de los factores antes señalados. Otro tema, objeto de debate como hemos visto, es la relevancia relativa de los efectos de barrio respecto a otros factores (estructurales, individuales, familiares) aspecto que no hemos abordado. Russafa y Els Orriols presentan similares tendencias con barrios de sus características, tanto españoles como extranjeros, de los que subrayamos dos enseñanzas. La primera, la importancia de la sociabilidad y su relevancia como recurso. Cuando en Russafa y Els Orriols se han dado problemas serios atribuidos al otro, reales o imaginarios, ha sido la trama asociativa vecinal, escolar y de ONG, la que ha afrontado la situación y procurado extender vías de comunicación y acomodación subrayando la común categoría de vecino. Una segunda enseñanza es constatar que las condiciones estructurales de convivencia constituyen un factor fundamental y que éstas, hoy, se han visto degradadas por la crisis, las políticas de devaluación interna y de austeridad. 


\section{BIBLIOGRAFÍA}

Arazo, Ma A. (2011): El Carmen y Russafa. Queridos barrios, Valencia, Ayuntamiento de Valencia.

ARBACI, S. (2008): «Hacia la construcción de un discurso sobre la inmigración en las ciudades del Sur de Europa». ACE, 8, pp. 11-38. http://revistes.upc. edu/ojs/index.php/ACE/article/view/2455

AuthiER, J-Y. (2007): « La question des « effets de quartier » en France. Variations contextuelles et processus de socialisation » en Authier, J-Y, Bacqué, $\mathrm{M}^{\mathrm{a}}$-E, Guérin-Pace, F (ed) Le quartier. Paris, La Découverte

AYUNTAMIENTO DE VALENCIA (2002): Indicador de renta de distritos y barrios de Valencia, Valencia.

Bacqué, M-H. y Denjean, J-M. (2006): «Les émeutes urbaines, signe d'échec de la politique de la ville?», Mouvements, 44(4):115-120.

Bacoué, M-H. y Fijalkow, Y (2006): « En attendant la gentrification: discours et politiques a la Goutte d'Or, Sociétés Contemporaines 63: 63-68.

Blanc, M., Authier, J-Y, Bidou, Ch., Garnier, J-P y Jacouin, J (2007): «Émeutes en banlieues: éditorial», Espaces et sociétés, 128-129:13-21.

Blanco, I y Subirats, J. (2011): «Exclusión social, territorio y políticas urbanas en España: una mirada comparada» en Iglesias, M. (ed) Políticas urbanas en España. Grandes ciudades, actores y gobiernos locales. Barcelona, Icaria.

Body-Gendrot, S. y Wintol De Wenden C. (2007): Sortir des banlieues. Pour en finir avec la tyrannie des territoires. Paris, Autrement

Bourdieu, P. (1993): "Effets de lieu », dans Bourdieu, P. (dir), La misère du monde. Paris, Seuil.

Cano Hila, A. B. y García Cabeza, M. (2012): «Políticas de acción comunitaria en las periferias urbanas. Problemas de transferibilidad», Gestión y Política Pública, 131-157

CeA, Ma A. y Valles, M. (2011): Evolución del Racismo y la Xenofobia en España. Informe 2011. Madrid, Ministerio de Trabajo e Inmigración. http:// explotacion.mtin.gob.es/oberaxe/inicio_descargaFichero?bibliotecaDato $\mathrm{Id}=216$

Cucó, J. (2013): «Poniendo a Valencia en el mapa global. Políticas, desarrollos urbanos y narrativas sobre la ciudad» en J. Cucó (ed.), Metamorfosis urbanas. Ciudades españolas en la dinámica globa., Barcelona, Icaria.

Delgado, M. (1998): «Dinámicas identitarias y espacios públicos». Afers Internacionals CIDOB, 43-44, pp. 17-33. http://www.cidob.org/es/content/ download/5483/54027/file/43-44delgado.pdf. 
Guillon, M. (1995): «Inmigration et centres urbains: le cas de Paris» en Gallisot, R. y B. Moulin (dirs) Les quartiers de la ségrétation. Tiers monde ou Quart monde?. Paris, Karthala. .

MansKi, C.F. (2000): «Economic analyses of social interactions». Journal of Economic Perspectives, 14, pp 115-136. http://www.wcas.northwestern. edu/nescan/manski_2000.pdf

Moncusi, A. (2009): Nuevos y viejos vecinos en dos barrios de Valencia. València, Ajuntament de València. http://www.uv.es/moncusi/NousiVellsveins011.pdf

Montero, A. (2013): Los recortes, la interculturalidad en el ámbito de la escuela y el papel de las ONG, TFM, Universidad de Valencia.

Moreras, J. (2011): «Sociabilidades reactivas en espacios urbanos multiculturales: los conflictos en torno a la apertura de mezquitas en Cataluña (1990-2008)», X Congreso de AECPA Murcia.

Musterd, S. y Andersson, R. (2005): «Housing mix, social mix and social opportunities». Housing Studies 40(6), pp. 761-790.

Musterd, S., Murie, A y Kesteloot,C. (eds) (2006): Neighbourghoods of poverty. Urban social exclusion and integration in Europe. Londres, Palgrave.

OBSERVATORIO DE LAS MIGRACIONES MADRID (2007): La concentración residencial de la población extranjera en la ciudad de Madrid. Madrid, Ayuntamiento de Madrid. http://www.madrid.es/UnidadesDescentralizadas/Inmigracion/EspInformativos/MadridConvive/Observatorio/Publicaciones/Publicaciones\%20anteriores/Serie\%20Informe/ informe_9.pdf

OBSERVATORIO DERECHO UNIVERSAL A LA SALUD COMUNIDAD VALENCIANA. ODUSALUD (2014): Informe 6. Recopilatorio anual de incidencias 2013. http://www.fadsp.org/documents/2014/20143101_Informe. pdf

Portes, A. y Rumbaut, R. (2010): América inmigrante. Barcelona, Anthropos.

Tapada-Berteli, T. y Arbaci, S. (2011): «Proyectos de regeneración urbana en Barcelona contra la segregación socioespacial (1986-2009): ¿solución o mito?. ACE, 17, pp. 187-222. http://upcommons.upc.edu/revistes/bitstream/2099/11085/9/ACE_17_SE_23.pdf

Torres, F. (2007): Nous veïns a la ciutat, València, Publicacions de la Universitat de València.

- (2011) La inserción de los inmigrantes. Luces y sombras de un proceso. Madrid, Talasa.

Torres, F. y García, P (2013): «La ciudad ocultada. Desigualdad y precarización en la Valencia global», en Cucó, P (coord.) La ciudad pervertida. Una mirada sobre la Valencia global. Barcelona, Anthropos. 
Toubon, J. C. y Messamah, K. (1990): Centralité immigrée. Le quartier de la Goutte-d'Or. Paris, L'Harmattan.

VALLET, L-A (2005): «La mesure des effets de quartier-voisinage: un objet important et difficile». Revue économique Sciences Po 56, pp. 363-369.

Van Ham, M., Manley, D, Bailey, N, Simpson, L y Maclennan, D (2012): "Neighbourhood effects research: new perspectives», en Van Ham, M et al (eds) Neighbourhood effects research: new perspectives. London, Springer.

Wacouant, L. (2007): Los condenados de la ciudad. Buenos Aires, Siglo Xxi. 